\title{
Cristóbal Vaca de Castro y la minería peruana en la encrucijada de las Leyes Nuevas
}

\author{
Miguel Molina Martínez
}

\begin{abstract}
Resumen
Este estudio profundiza en el conocimiento del esfuerzo legislativo llevado a cabo por Cristóbal Vaca de Castro en materia minera. Se centra en las ordenanzas para las minas de oro y plata promulgadas en 1543. Estas leyes se inscriben en el contexto del régimen encomendero imperante en la época y no se entienden fuera del debate suscitado por el mismo. Pretenden dar respuesta al problema de la población indígena encomendada y que es destinada a trabajar en las minas. En este sentido, consagran el principio, en total sintonía con la voluntad de la Corona y la legislación anterior, de que los indios no pueden ser enviados a los centros mineros, salvo que medie su propia voluntad. Son un buen exponente de la preocupación humanitaria del monarca y su Consejo de Indias en el momento justo del triunfo de las Leyes Nuevas y de las tesis de Las Casas. Se evalúa el grado de sintonía de su autor con el contenido de las mismas.
\end{abstract}

Palabras clave: Ordenanzas, minería, Vaca de Castro, Perú, Leyes Nuevas.

Abstract

CRISTÓBAL VACA DE CASTRO AND PERUVIAN MINING AT THE CROSSROADS OF THE NEW LAWS

This study focuses on the legislative efforts by Cristóbal Vaca de Castro regarding mining. It focuses on the regulations for the gold and silver mines enacted in 1543. These laws lie within the context of the prevailing regime at the time, and cannot be understood without the debate this regime created. They aimed to address the problem of the indigenous population sent to work on the mines. In that regard, these new laws outline the principle, in clear harmony with the will of the Crown and the previous legislation, that Indians cannot be sent to mines against their own will. They are a clear example of the humanitarian concerns of the monarch and his Council of the Indies, at a time when the New Laws and the thesis by Las Casas were triumphant. The present work evaluates the degree of alignment of the author with their content.

Keywords: Ordinances, mining, Vaca de Castro, Peru, New Laws.

Miguel Molina Martínez - Departamento de Historia Moderna y de América, Universidad de Granada. Correo-e: mimolina@ugr.es 
El interés que el historiador ha mostrado acerca de la labor legislativa en asuntos de minas llevada a cabo por Cristóbal Vaca de Castro ha sido considerablemente menor que el dedicado a otros ámbitos de su gestión política. En realidad sólo de forma tangencial se ha hecho mención a sus ordenanzas de minas, circunstancia que también es válida en lo que concierne a sus ordenanzas de tambos ${ }^{1}$. Ello justifica este trabajo cuya finalidad va más allá de una simple exposición del contenido de aquel código minero. Nuestro propósito persigue ofrecer un análisis contextual que dote de sentido al trabajo de Vaca de Castro en esta materia y valorar el alcance del mismo en un Perú convulsionado por las guerras civiles. En efecto, no pueden entenderse sus ordenanzas de minas al margen del debate suscitado por el sistema de encomiendas vigente en la época ya que su objetivo no era otro que dar respuesta al problema de la población indígena encomendada que era destinada a trabajar en las minas. El texto, en consonancia con las directrices reales, enfatiza la prohibición de que los indios puedan ser enviados a los centros mineros si no es por su propia voluntad. Son, por tanto, un buen exponente de la preocupación humanitaria del monarca y su Consejo de Indias en el momento justo del triunfo de las Leyes Nuevas y las tesis lascasistas. Por otro lado, pueden considerarse como un primer intento de sistematización de la incipiente explotación minera peruana en una fase temprana, previa al descubrimiento de los grandes yacimientos argentíferos que transformaron la esencia misma del virreinato y las relaciones atlánticas.

\section{Un necesario contexto histórico}

La década de 1540 se manifestó en Perú como una de las épocas de mayor convulsión. La rivalidad entre pizarristas y almagristas adquirió un alto grado de violencia y llegó a condicionar el devenir de aquellos años hasta el punto de proyectarse en un enconado escenario de guerras civiles. Vaca de Castro, oidor de la Audiencia de Valladolid, se vio envuelto en el conflicto desde el momento en que el rey - recomendado por el presidente del Consejo de Indias, fray García de Loaysa - le designó juez comisionado para mediar entre Francisco Pizarro y los seguidores de Diego de Almagro, muerto a manos de aquél. La llegada del licenciado a Perú tuvo lugar pocos meses después de que los almagristas acabaran con la vida del gobernador Pizarro en junio de 1541. El dramático suceso le convirtió en la máxima autoridad peruana, toda vez que previsoramente el monarca le había nombrado gobernador de Perú en el supuesto de que Pizarro falleciera. Tal tesitura le llevó a enfrentarse directamente con Almagro el Mozo y zanjar el conflicto tras su victoria en la batalla de Chupas el 16 de septiembre de 1542. De esa forma dio comienzo a un periodo de gobierno de apenas dos años, entre 1542 y 1544, plagado de luces y sombras, que concluyó con una fulminante destitución a manos del virrey Blasco Núñez Vela (García Rodríguez 1957; Viforcos Marinas y Paniagua Pérez 1991). 
La caótica situación heredada, junto a la gravedad de los retos políticos y sociales a los que se hubo de enfrentar, condicionaron sobremanera su gestión. La tarea que tenía ante sí era ciertamente comprometida. No sólo le competía la pacificación de un territorio gravemente dividido en bandos irreconciliables de españoles, sino también la reconducción de las relaciones entre encomenderos e indígenas, muy criticadas desde el ámbito religioso y contempladas con especial recelo por la Corona. Respecto a la primera cuestión, su triunfo en Chupas pareció despejarle el panorama bélico, aunque los almagristas nunca le perdonarían su política. Respecto a lo segundo, el problema derivó hacia frentes a los que no supo o no quiso abordar en el sentido que proponía la Corona. De esta forma, la cuestión encomendera y el debate sobre la condición indígena se interpusieron como un serio obstáculo para la ejecución de sus propias estrategias de gobierno. En esta dinámica cabe entender la publicación de sus ordenanzas de minas.

En los albores de 1540 la corriente humanitaria a favor del indio estaba plenamente consolidada, tras el impacto de las denuncias de fray Antonio de Montesinos y el decisivo compromiso de Bartolomé de las Casas y otros religiosos. Había sido necesario un largo y profundo debate que se remontaba a los tiempos del propio Colón. Numerosas disposiciones reales jalonan las tensas relaciones entre Corona y conquistadores a propósito del indio sin que ninguna de ellas lograra zanjar el problema. Las leyes de Burgos de 1512 no pasaron de ser una declaración de buenas voluntades. Las ordenanzas de Granada de 1526, ya con el dominico fray García de Loaysa al frente del Consejo de Indias, trataron de fijar con más firmeza las directrices reales. Prohibieron hacer esclavos, forzar a los indios a trabajar en las minas y prescribieron que los encomenderos respetaran la condición libre del indio (Osuna Fernández-Largo 1991: 93). Su inobservancia ofreció nuevos argumentos a los detractores del régimen encomendero y sentó las bases del ordenamiento de 1542. En el mismo Cuzco, su obispo, fray Vicente de Valverde, se erigió en protagonista de esta nueva política y en su condición de protector de naturales no perdió la oportunidad de denunciar los abusos de aquella sociedad (Hampe Martínez 1981: 109-153; Santisteban Ochoa 1948). Una prueba de que el maltrato al indígena era moneda común en la región, no obstante la legislación proteccionista en vigor, es el contenido de la extensa carta que remitió desde Cuzco al emperador el 20 de marzo de 1539 (Archivo General de Indias [AGI], Patronato, 192, nº 1, Ramo 19). En ella urgía a Carlos $\mathrm{V}$ que los indios libres y los yanaconas no fuesen encomendados y que viviesen en libertad, que no fuesen obligados a trabajar en las minas, ni compelidos a servir como porteadores, ni abandonar sus tierras. Por otro lado, ante la precaria situación del proceso evangelizador demandaba al soberano el envío de dominicos y franciscanos para cubrir las necesidades misioneras de la región. La petición tuvo una rápida respuesta del rey que se concretó en la organización de una expedición de dominicos en 1540 al Perú, entre cuyos integrantes figuraban fray Tomás de San Martín y fray Domingo de Santo Tomás. Este último estaría llamado 
a jugar un papel decisivo en la crítica encomendera y la defensa del indio (LópezOcón Cabrera 1987; Hampe Martínez 1990: 355-402).

En este contexto humanitario cobran sentido las instrucciones dadas a Vaca de Castro. Dichas instrucciones abarcan un extenso documento que incluye hasta 49 puntos en los que se perfilan las directrices de su actuación en tierras peruanas (Real Cédula de D. Carlos a Cristóbal Vaca de Castro, conteniendo las instrucciones que ha de seguir en la provincia del Perú para averiguación y remedio de los excesos allí cometidos y para el buen trato de los indios especialmente. Madrid, 15 de junio de 1540. AGI, Lima, 566, Libro IV; Hanke 1978: 20-36). Para nuestro estudio destacan aquellas dirigidas a poner orden en el estado de las encomiendas, a perseguir la explotación de los indios, cortar los abusos de los españoles y castigar a los infractores:

"Porque somos informados que en dicha provincia se han hecho por los españoles que en ella han residido y residen muchos malos tratamientos a los naturales della, así en tomarles sus oros y haciendas y mujeres e hijos por fuerza e contra su voluntad, como en haber muerto a algunos en tormentos y molestias que les han hecho por les sacar oro... y nos, por estas causas principalmente y porque redunda en despoblación de la dicha tierra y daño de nuestro estado y patrimonio, somos muy deservidos y tenemos voluntad que se castigue lo pasado y remedio para adelante; y que los dichos indios sean tratados como cristianos libres, vasallos nuestros...; y daréis orden que de aquí en adelante no se haga mal tratamiento algunos a los dichos indios, sino que sean bien tratados e industriados en las cosas de Nuestra Santa Fe Católica e para ello haréis las instrucciones $y$ ordenanzas que os parecieren ser necesarias y convenientes...».

La cita arroja luz sobre cuáles eran los objetivos últimos de la Corona en materia indigenista y la trascendencia de la misión que se encargaba a Vaca de Castro. Aquélla daba por ciertos los abusos cometidos contra los indios y no le faltaban argumentos para ello, habida cuenta de los múltiples testimonios llegados a la Corte desde América. La cruzada de Las Casas en este sentido había ganado la voluntad del rey y la de un sector importante de los consejeros (Hanke 1967: 172). La redacción de este punto de las instrucciones refleja con claridad el alcance del lenguaje lascasiano y marca el nuevo rumbo de la política estatal que culminó con la promulgación de las Leyes Nuevas de 1542, consideradas como la gran reforma carolina (Pérez de Tudela Bueso 1958: 463-506; Muro Orejón 1959). Otros muchos pasajes de las instrucciones dadas al licenciado volvían a insistir en la defensa de los naturales y el buen trato debido como vasallos que eran de la Corona. Desde que en 1533 Pizarro fuera autorizado para repartir indios, las encomiendas se habían convertido en un mecanismo de servicio personal abierto a la explotación masiva de los naturales (Puente Brunke 1992: 19). Los esfuerzos del monarca por regular la capacidad de trabajo y tributación de los indígenas habían resultado hasta entonces infructuosos. Tal es la razón por la que el problema del indio bajo el régimen encomendero terminó siendo parte medular de las instrucciones y su destinatario asumió el papel 
protagonista de la reforma, al tiempo que supervisor de lo actuado por Pizarro en esta materia. Como se verá, el servicio de los indios en las explotaciones mineras fue uno de los temas más críticos y controvertidos, lo que motivará la redacción de las ordenanzas de minas como un intento del licenciado para reconducir la situación que halló en tierras peruanas.

\section{Los albores de la minería peruana colonial}

Cuenta el cronista López de Gómara que Vaca de Castro residió en Cuzco un año y medio «y en aquel tiempo se descubrieron riquísimas minas de oro y plata» (López de Gómara 1979 [1552], CL: 218). El propio Castro confirma este hecho en una carta al rey fechada en Cuzco el 24 de noviembre de 1542 cuando escribe que «de pocos meses acá se ha descubierto mucha copia de minas de oro e muy ricas, de que se saca muy grande cantidad, y es tan bueno que en lo que se ha fundido agora en esta ciudad, que hice hacer la fundición en mi presencia en la casa de ella, ha habido oro de veinte e tres quilates y dos tomines» (Cartas de Indias 1974, II: 488).

En efecto, antes de que las minas de Potosí dominaran el universo minero peruano, el interés de los españoles hacia los yacimientos auríferos y argentíferos se había convertido en una cuestión prioritaria. Las minas de oro fueron las que sedujeron en primer lugar a los conquistadores instalados en Cuzco. El tesoro de Atahualpa y las sucesivas noticias acerca de la abundancia de oro en la región movilizaron hacia su búsqueda y explotación. El descubrimiento de minas en el valle de Chuquiabo vino a demostrar el potencial de riqueza que se presumía. Según Cieza de León, allí «fue donde en los años pasados se sacó gran cantidad de oro de mineros ricos que hay en este lugar. Los incas tuvieron por gran cosa a este Chuquiabo» (Cieza de León 1984 [1553], CVI: 369). El que fuera secretario de Pizarro, Pedro Sancho de la Hoz, recoge información detallada sobre estas minas a las que describe de esta forma:

«Están las minas en la caja de un río a la mitad de la altura hechas a modo de cuevas a cuya boca entran a escarbar la tierra... Las gentes que aquí sacan oro podrán ser hasta quinientos entre hombres y mujeres y estos son de toda esta tierra de un cacique veinte $y$ de otro cincuenta $y$ de otro treinta y de otro más o menos según que tienen $y$ lo sacan para el señor principal y en ello tienen puesto tanto resguardo que de ningún modo pueden robarse cosa alguna de lo que sacan porque alrededor de las minas tienen puestas guardas para que ninguno de los que sacan oro puedan salir sin que lo vean... Hay otras minas adelante de estas y otras hay esparcidas por toda la tierra a manera de pozos profundos como de la altura de un hombre [...]. Pero las más ricas y de donde se saca más oro son las primeras que no tienen el gravamen de lavar la tierra. Y por causa del frío no lo sacan de aquella mina sino cuatro meses del año desde la hora del mediodía hasta cerca de ponerse el sol» (Sancho de la Hoz 1917: 197-198). 
Tras la conquista Francisco Pizarro las tomó para sí, junto con los indios yanaconas que con anterioridad las venían trabajando para el inca. Ya en tiempos de Vaca de Castro, la actividad aurífera ofrecía un extraordinario desarrollo a tenor de lo que refiere el inca Garcilaso en el capítulo de su Historia del Perú, dedicado al buen gobierno del licenciado Vaca de Castro:

«Se descubrieron [escribe] riquísimas minas de oro en muchas partes del Perú; pero las más ricas fueron al Oriente del Cuzco en la provincia llamada Collahuaya, que los españoles llaman Caravaya, donde sacaron muy mucho oro finísimo de veinte y cuatro quilates, y hoy se saca todavía, aunque no en tanta abundancia, Al poniente del Cuzco en la provincia que llaman Quechua, que contiene muchas naciones del mismo nombre, en la parte que llaman Huallaripa, descubrieron otras minas de oro, no tan fino como el de Collahuaya, aunque todavía llegaba a los veinte quilates poco más o menos... Llamamos oro en polvo el que sacan como lo hallan, que es como la limalla de los herreros, y otro más grueso, como el afrecho que sacan de la harina, entre lo cual también se hallan algunos granos que llaman pepitas, como pepitas de melón y calabaza, que tienen a tres, cuatro, seis, ocho ducados... De tanto oro como se sacaba, acudía grandísima cantidad a las fundiciones para el quinto de Su Majestad, que era un tesoro innumerable que le daba de cinco marcos uno, de cinco pesos uno, y así hasta el postrer maravedí... Con estas prosperidades y con un Gobernador tan cristiano, tan caballero, tan prudente, tan amigo de acertar en el servicio de Dios Nuestro Señor y en el de su Rey, florecía aquel Imperio cada día de bien en mejor» (Garcilaso de la Vega 1960 [1617], libro 3º, capítulo XIX: 210).

Por su parte, las minas de plata se localizaron principalmente en Porco y La Plata, ciudades fundadas por Gonzalo Pizarro en 1538 y 1539, respectivamente, en la región que tomaría el nombre de Charcas en alusión a uno de los grupos nativos que la habitaban (Barnadas 1973: 34). Tanto Gonzalo como Hernando Pizarro promovieron su explotación desde el primer momento y destinaron a ellas, del mismo modo, mano de obra indígena captada a través de los repartimientos. Otro tanto haría el resto de colonos propietarios de minas. Comenzó así una manera de captación laboral que culminaría con la implantación del sistema mitayo en la década de 1570 y que consagró la utilización de la mano de obra india de forma coercitiva en las explotaciones mineras. A la llegada de Vaca de Castro a Perú la práctica generalizada era que los españoles se sirvieran de los yanaconas y de los indígenas de su encomienda para destinarlos al servicio de minas, casi siempre soslayando las leyes que prohibían tales procedimientos. Aunque una real cédula, fechada en Zaragoza el 8 de marzo de 1533, equiparaba a los yanaconas con los esclavos al permitir su compra-venta, lo cierto es que en 1541 la Corona había cambiado de criterio y decretado su libertad (Real Cédula de Carlos V a Vaca de Castro, Fuensalida, 7 de octubre de 1541. AGI, Lima, 566, libro IV, 243v-244).

Sin embargo, las viejas costumbres seguían presentes afianzando la convicción de que el trabajo forzado en las minas había surgido en el ámbito de la encomienda y que los encomenderos eran quienes se beneficiaban de semejante práctica 
y la defendían (Barnadas 1973: 286). Razones legales tenían toda vez que ya en 1539 el oficial real Illán Suárez de Carvajal otorgó licencia a los Pizarro para llevar indios de su encomienda a sus minas de oro y plata (Barnadas 1973: 263) y a ello se remitían para continuar haciéndolo. Sin embargo, las directrices indigenistas de la Corona no tardaron en imponerse y a la altura de 1540 eran ya una corriente bien arraigada. En esas fechas el comportamiento del gobernador Francisco Pizarro en lo que respecta a los repartimientos realizados entre los suyos y el trato dispensado a los nativos merecía serias reservas y había sido puesto en tela de juicio. Baste releer el contenido de las instrucciones dadas a Vaca de Castro en junio de 1540 para percatarse de su débil posición en la Corte, a pesar de la protección que le dispensaba García de Loaysa. Las sucesivas reales cédulas remitidas a lo largo de 1541 a las autoridades peruanas sobre preservar la libertad de los indios, impedir que sean enviados a las minas o que los encomenderos no alquilen a sus indios para tales trabajos señalan el nuevo rumbo de la política (Zavala 1978: 7)2. A mayor abundamiento, las Leyes Nuevas de 1542 vendrían a ratificar poco después tales directrices al prohibir la esclavitud indígena, la práctica de servirse de los indios contra su voluntad y, en definitiva, asestar un duro golpe a la supervivencia del régimen de encomiendas. Especialmente significativas eran sus cláusulas 21, 22 y 30 . En concreto, esta última era tajante en cuanto a la continuidad del sistema y ordenaba

"que de aqui adelante ningund visorrey gouernador abdiencia descubridor ni otra persona alguna no pueda encomendar yndios por nueva prouission ni por rrenunciacion ni donacion venta ni otra qualquiera forma modo ni por vacacion ni herencia sino que muriendo la persona que touiere los dichos yndios sean puestos en nuestra rreal corona y las abdiencias tengan cargo de se ynformar luego particularmente de la persona que murio y de la calidad della y sus meritos y seruicios y de como trato los dichos yndios que tenia y si dexo muger y hijos o que otros herederos y nos embien la rrelacion y de la calidad de los indios y de la tierra para que nos mandemos proueer lo que sea nuestro seruicio» (Muro Orejón 1959: 575) ${ }^{3}$.

No obstante toda la legislación vigente al respecto, Vaca de Castro obvió en gran medida su contenido y apenas modificó la situación heredada, sobre todo tras apropiarse de las encomiendas de Pizarro y permitir la continuidad del trabajo de los indios encomendados. Todo ello con evidente incumplimiento de las instrucciones recibidas desde la península y otras disposiciones legales.

\section{Las ordenanzas de minas de Vaca de Castro}

En abril de 1543 vieron la luz las ordenanzas de minas de oro, redactadas por Vaca de Castro (Ordenanzas de minas hechas en la ciudad de Cuzco en 12 de abril de 1543. Real Academia de la Historia [RAH], Colección Mata Linares, XXIII: 89-128; Zavala 1978: 9-11). Fueron completadas a finales de mayo con otras disposiciones para las minas de plata (Ordenanzas añadidas por el gobernador Vaca de Castro sobre 
las minas de plata. Cuzco, 31 de mayo de 1543. RAH, Colección Mata Linares, XXIII: 129-134). Se trataba de un proyecto dirigido a reglamentar este sector económico en auge y acomodarlo a las resoluciones del monarca. Tal medida era absolutamente necesaria, no sólo por la ausencia de una normativa precisa al respecto, sino también por los abusos y desórdenes con los que se trataba a la mano de obra. La base jurídica sobre la que se sustentan dichas ordenanzas no es otra que la que alienta las instrucciones y provisiones reales recibidas hasta la fecha. Principalmente la real cédula, dada en Madrid el 24 de abril de 1540, por la que concedía a los vecinos de ella potestad para sacar oro y plata de las minas valiéndose de los naturales del país, siempre que éstos quisieran libremente hacerlo (AGI, Lima, 565, libro 3, f. 209). También la real provisión de 26 de julio de 1541, promulgada en Talavera, prohibiendo tajantemente que nadie «ni directa ni indirectamente sean osados de echar indios algunos a las minas», bajo penas de perder oficio y bienes en caso de incumplimiento (AGI, Lima, 566, lib. 4, fs. 201-201v). Aunque las Leyes Nuevas ya habían sido aprobadas para entonces, Vaca de Castro desconocía su revolucionario texto cuando terminó la redacción de este código minero. De hecho la noticia de la publicación de las Leyes Nuevas no llegó a Perú hasta mediados de 1543 por boca de Diego de Aller, un criado de Vaca de Castro. La alarma y el recelo que ello provocó entre conquistadores y encomenderos sería de tal envergadura que ocasionarían un nuevo conflicto y la muerte del virrey Blasco Núñez de Vela que llegaba al Perú para su puesta en práctica.

Las ordenanzas de minas fueron leídas en cabildo público el mismo 13 de abril de 1543 y publicadas en la plaza del Cuzco el 21 de junio de ese mismo año. En el preámbulo explican que su finalidad era «proteger a los indios de los abusos que con ellos se cometían». Del mismo modo, dejaban constancia de la situación que pretendían corregir:

«Es cierto que desde el principio que vinieron los españoles había costumbre de enviar a los indios a trabajar en las minas, y el mismo Emperador había dado alguna cédula a los vecinos de Cuzco para que pudieran hacerlo. Pero como las órdenes de S.M. eran apremiantes para que no se manden los indios a trabajar a las minas a no ser que ellos vayan de su voluntad, y aun así ha de regularse el permiso para evitar abusos, y para ello damos las siguientes ordenanzas».

Las leyes que siguen inciden, por tanto, de forma directa en estas cuestiones. La primera cláusula contempla la prohibición de forzar al indio a servir en las minas y reglamenta el trabajo voluntario: «Que aquellos que tengan indios que dicen que quieren ir voluntariamente a las minas los lleven delante de la autoridad... y sean preguntados si van de su voluntad o no. Si estuvieran lejos de donde está la justicia, que vengan los caciques y encargados a responder por ellos. Y cuando vayan a las minas, que el alcalde de minas certifique de que van voluntariamente».

También es responsabilidad del alcalde de minas que los naturales sean bien tratados y para tal fin se articulan medidas precisas: construcción de casas en los yacimientos para el descanso de los indios; obligación de que coman antes de 
salir a trabajar y vuelta para cenar; provisión semanal de raciones de carne, maíz, sal, agí y coca, con imposición de penas en caso de incumplimiento. No hay ninguna mención al salario que pudieran cobrar los trabajadores; los caciques y sus mujeres recibirán ración doble y no se les puede mandar a trabajar; prohibición expresa de que nadie "tome o esconda las mujeres de los caciques o de los otros indios ni se echen con ellas»; prohibición que se extiende a tomar indio o india que pertenezca a otro.

Además, se reglamentan las condiciones del régimen laboral, señalando los cupos, desplazamiento y trato. En tal sentido, estipulan que el porcentaje anual de indios que pueden incluirse en el repartimiento de minas sea el 25 por ciento y que «no salgan viejos ni muchachos de poca edad, que éstos no cuentan para el trabajo». Si se sobrepasara esta cifra, los infractores serían castigados con 300 pesos la primera vez y pérdida de los indios, la segunda. El tiempo de trabajo de los indios en las minas se limita a cuatro meses al final de los cuales deben ser reemplazos por otro cupo. Para su estricto cumplimiento determina que «los que entraren con gente en las minas para trabajar en ellas sean obligados a irse a registrar ante el alcalde de dichas minas, y éste asiente el mes, día y año en que entran; y cumplidos los cuatro meses los mande ir a sus casas, y la persona que los tuviere a su cargo los lleve ante el alcalde para que vea si se van todos».

Los trabajadores no pueden ser desplazados a minas situadas a más de 60 leguas de sus lugares de origen y se prohíbe que carguen con bastimentos. Excepcionalmente, cuando el terreno impidiera el acceso de animales de carga, se permite que los indios carguen con no más de 30 libras y todo bajo supervisión del alcalde de minas. Aun así regula con detalle esta cuestión, sin duda objeto de los mayores abusos. En tal sentido establece que: «el alcalde de minas tenga mucho cuidado de ver y saber si los carneros y bestias pueden entrar cargados en las minas; $y$ si en ellos se pudiese llevar, no se carguen los indios, y si alguna persona los cargare lo haga saber al gobernador o a su lugarteniente para que provean en ello. Y si los caminos fuesen malos, lo haga saber para que el gobernador los haga arreglar para que no se carguen los indios. Y si alguna persona cargare los indios habiendo caminos por donde las bestias puedan pasar, tenga penas».

Con buen criterio establece la ordenanza que «los indios de tierra fría no vayan a coger oro a tierra muy caliente, ni los de aquí a tierra fría». Tanto los caciques como los indios de repartimiento debían abandonar las minas desde el 15 de diciembre hasta el 15 de abril, época de «muchas aguas y van crecidos los ríos y no se puede coger oro en ello». Se establecen castigos para los delitos que cometan los indios que sirven en las minas, aunque aclara que nadie pueda castigar «en las cosas que las ordenanzas lo prohíben».

En cuanto al cuidado espiritual de los naturales, ordena que se construya iglesia en las minas y haya clérigo para la instrucción y los servicios religiosos (oraciones diarias, misa dominical y fiestas de guardar, etc.). Entre las ocupaciones del 
clérigo estaban también las de convertir y bautizar a los indios, especialmente a los que estuvieran en peligro de muerte, así como enterrar a los muertos.

Además, las ordenanzas se detienen en aspectos relativos al denuncio de una mina, su toma de posesión y estacado en prevención de litigios futuros. Por último, establecen diferencias entre los yacimientos auríferos, según se encontraran ubicadas en las cabeceras de los ríos, en cascajales, arroyos o barrancadas.

Por lo que se refiere a la adición introducida relativa a las minas de plata, llama la atención su contenido breve. No incluye ninguna ley que reglamente el trato al indígena ni su trabajo por lo que deja entrever que mantiene su vigencia lo establecido para las minas de oro. Su principal preocupación se centra en reglamentar los aspectos relativos al descubrimiento, reparto y tamaño de los yacimientos.

\section{Valoración y significado político de la reforma minera}

La eficacia y grado de cumplimiento de estas ordenanzas fue en la práctica nula. Su impacto tuvo un alcance muy limitado, ya que los mineros arbitraron diferentes mecanismos para burlarlas (Helmer 1959: 127). La iniciativa de Vaca de Castro no pasó de ser un compendio de buenas intenciones bajo la presión de la Corona y en un contexto dominado por las tesis lascasistas. La crítica al sistema de encomiendas y la lucha por sacar al indio del mismo planean sobre todo el texto y en tal sentido cabe entenderlo como resultado del estado de opinión imperante en la Corte a principios de la década de 1540 . Siendo esto así, es pertinente preguntarse sobre la actitud del propio Vaca de Castro acerca de los preceptos que estableció y el compromiso que asumió hacia ellos. En este sentido la documentación disponible sugiere la escasa identificación de aquél con sus ordenanzas. Lo estipulado en ellas contradice su comportamiento abriendo un serio abismo entre la formulación teórica y la práctica cotidiana. La política del gobernador estuvo lejos de lo que el monarca demandaba en relación a las polémicas encomiendas y el buen trato al indio. Su comportamiento delata que estuvo más cerca al de un encomendero que al de un gobernante enviado para corregir abusos y encauzar el sistema conforme a los dictados del Consejo de Indias. El retrato que de él traza Juan Pérez de Tudela como un fariseo devoto y ambicioso encaja en este perfil y además afianza la imagen de un hombre que apoyó con toda su autoridad la conservación del orden encomendero. En su opinión, la actitud del licenciado consistió finalmente en «favorecer ampliamente a amigos y paniaguados o a los mejores postores, con los repartimientos vacantes, contándose a sí propio como el primero y destacadísimo entre sus afectos; en echar cuantos indios hizo falta a las ricas minas de oro de Carabaya, recién descubiertas» (Pérez de Tudela Bueso 1963: XXXII).

También sus contemporáneos eran conscientes de las verdaderas intenciones del licenciado y no dudaron en manifestar su descontento, más o menos interesado. Uno de ellos, Francisco Maldonado a la sazón regidor del cabildo de Cuzco, 
no tuvo reparo en transmitir al monarca su mala gestión política, la que conducía al país a un estado de mayor alboroto y crisis. En una carta, fechada el 9 de marzo de 1543, solicitaba la destitución del gobernador porque «ni los naturales ni los españoles que acá estamos en servicio de S.M. no tenemos ningún reposo ni quietud, sino más alterados con la venida del licenciado Vaca de Castro» (Archivo Histórico Nacional [AHN], Colección de documentos de Indias, Diversos-Colecciones, 22, no 42). En esta misma misiva denunciaba abiertamente la mala práctica que seguía Vaca de Castro con los indios de encomienda: «Todos los indios de los que se hallaron en la muerte del Marqués y después en favor de don Diego, teníalos sacando oro en las minas, y todo aquel oro que se les tomó, que no ha sido poco..., lo tiene en sí el licenciado Vaca de Castro... Toda la tierra y gran suma de repartimientos que están vacos se la tiene en sí y no los ha provisto a nadie... sino que él solo se sirve de todos ellos».

En el mismo sentido se expresaba el cabildo y oficiales reales de Lima. Firmaron una carta el 6 de marzo de 1543 en la que reclamaban a Carlos V que se pusiera en aquella ciudad un tribunal de Audiencia para la seguridad y buen gobierno del Perú; consideraban que era necesario tomar residencia al licenciado Vaca de Castro al que acusaban directamente de haberse apropiado de todos los indios vacantes que habían tenido los Pizarro con la finalidad manifiesta de amasar una gran fortuna (AGI, Patronato, 192, n ${ }^{\circ} 1$, Ramo 30). Por su parte, el contador Juan de Cáceres, una víctima más de sus atropellos, hizo llegar también al monarca una encendida carta en la que lo calificaba de mentiroso, vanaglorioso, mal cristiano y codicioso. Y detallaba: «Tiene en sí todo lo habido de los rebeldes, de que pudiera haber aplicado al fisco doscientos mil castellanos; $y$ todos sus repartimientos de ellos, tiene en su cabeza y de sus criados; y algunos repartimientos vende públicamente. El se trata como Rey y no se acuerda de las necesidades de S. M. De manera que dando de sí la tierra tanto, no habrá en todo este año para acabar de pagar los gastos de la guerra pasada» (AGI, Patronato, 194, Ramo 66).

Un almagrista declarado como Alonso de Medina sacó rédito de las arbitrariedades de su rival para desahogarse ante el presidente La Gasca en estos términos: «El dicho Vaca de Castro entrando en la ciudad de Cuzco, como atrás tengo dicho, comienza a poner su casa de mercaduría y desollar los naturales por sacárselo, y echa a minas de Caravaya a los repartimientos; y los vecinos como vieron que la cabeza destruye el reino, echaron el reino, echaron ellos los repartimientos de CX leguas y hacíanlos ir cargados con sus hijos y casas a cuestas dando gemidos por esos caminos y el bellaco del minero les tomaba la comida y el pobre indio no tenía con que volver a sus negros pueblos» (Pérez de Tudela Bueso 1964: 40).

El virrey Blasco Núñez de Vela, receptivo a ésta y otras informaciones, contribuyó a dar mayor resonancia a la controvertida actuación de su predecesor. Encontrándose todavía en Panamá hizo saber a Carlos V por medio de una carta datada el 15 de febrero de 1544 la desconfianza que le merecía, poniendo en tela de juicio su proceder en el gobierno. En sus propias palabras: 
«Lo que yo he podido sentir es que Vaca de Castro ha puesto mucha cantidad de indios en su cabeza y llevado los tributos de ellos, que dicen que son en gran cantidad; $y$ pretendió que todos los tributos de los indios que tenía en su cabeza don Francisco Pizarro le pertenecían a él desde el día en que el dicho don Francisco murió... Oigo que ha dado lugar a que se vendan los indios de unos a otros y él ha proveído a algunos, recibiendo dineros de quien los encomendó... Maravillado estoy de que el licenciado haya echado indios a las minas, cuando en los asientos que se tomaron con Pizarro se insertó provisión que perdiese los indios quien los echase a las minas» (Pérez de Tudela Bueso 1964: 187).

En el claroscuro de la semblanza que hiciera Cieza de León se contienen esos mismos rasgos que remiten a la ambición y vanagloria del personaje. En su opinión, Vaca de Castro "no entendía en más que en buscar dineros para henchir la gran codicia que tenía...; procuraba de allegar tesoros por vías no licitas...; de los mejores repartimientos que había puso en su cabeza, e de ello e de los demás indios procuraba haber dineros...; participó en los vicios de presunción vana e vanagloria, e codicioso» (Cieza de León 1985 [1881], LXXXIII: 263).

Otros muchos testimonios podrían aducirse pero baste esta muestra para percatarse de lo distantes que estaban las normas recogidas en sus ordenanzas de minas de su comportamiento cotidiano. Como sostiene Jesús Paniagua «hay claras diferencias entre su vida privada y su vida pública, entre su equilibrada vida como jurista y su pragmatismo de gobernante, no está lejos de ser lo que podríamos denominar un "hipócrita", pero esto entraba dentro del panorama normal de la época" (Paniagua Pérez 1988: 72).

Muy reveladores de sus auténticos objetivos fueron los términos en los que se dirigía a su esposa, doña María de Quiñones, en una carta remitida desde Cuzco el 28 de noviembre de 1542. En ella quedaban al descubierto sus verdaderas intenciones en el gobierno, al tiempo que le advertía sobre el sigilo y secreto que debía tener con todos los caudales que le remitía por vía indirecta. Con toda naturalidad le aconsejaba «fingir necesidad y que yo no he enviado nada..., mientras menos viere el rey y sus privados, más mercedes me harán» (Cartas de Indias 1974, II: 499). Su pretensión de crear un mayorazgo, unido a sus fuertes convicciones feudales sobre la base del disfrute de encomiendas con el consiguiente servicio laboral indígena, guiaban una conducta bien arraigada entre el grupo de conquistadores y primeros pobladores en América. Pero con ello no sólo contradecía la nueva política real, sino que convertía en papel mojado el texto de sus mismas ordenanzas de minería. Algunos de los 21 cargos que se insertan en el proceso judicial abierto en 1545 en España por el fiscal Juan de Villalobos revelan la desenvoltura con que contravino ciertos capítulos de aquéllas ${ }^{4}$. La primera acusación delata este hecho a tenor de su literalidad: "Que no pudiendo llevar cargados los indios y debiendo castigar a los que hiciesen lo contrario, el dicho licenciado Vaca de Castro los había llevado cargados como a bestias más de ciento de ellos, con sus ropas y haciendas, y de sus criados más 
de trescientas leguas sin les dar cosa alguna, de que habian recibido gran daño y muchas muertes».

La acusación sexta es aún más incontestable y transgrede todo cuanto se venía legislando desde el Consejo de Indias relativo al servicio personal en las minas: "Que estando proveído que no se echasen indios a las minas, y habiendo él de mandar que se guardase así, no lo había hecho, antes había mandado echar mucha cantidad de indios a las minas, especialmente a las de la provincia de Carabaya y otras muchas minas, donde murieron muchos indios y sacaron más de cien mil castellanos y no les había pagado los jornales, y por ello había incurrido en las penas en que incurrían los que echaban indios a las minas».

En el mismo sentido, el cargo duodécimo vuelve a insistir en la inobservancia de las leyes: «Que el dicho licenciado Vaca de Castro no había observado nuestras cédulas reales que le fueron dadas cerca del buen tratamiento de los indios y que no les consintiese cargar ni echar a las minas y tasase los tributos, lo cual habia hecho por su propio interés por cargar él los indios y echarlos a las minas y llevarle los tributos que les había llevado».

Resulta interesante constatar cómo él mismo argumentó tales actuaciones en su larga y bien cuidada defensa. No sólo admitió ser ciertos aquellos comportamientos, sino que los justificó y alegó con naturalidad que se vio obligado a ponerlos en práctica dada la situación del país y, especialmente, en razón de la recompensa debida a quienes habían arriesgado vida y bienes para la conquista de la tierra. En sus propias palabras, «quitarles los indios en aquellas circunstancias, en que todos estaban esperando mercedes por haber ayudado con sus bienes y personas a la guerra, hubiera resultado muy duro». Teniendo en cuenta estas consideraciones es posible afirmar que Vaca de Castro se postula como un digno portavoz del llamado derecho premial, según el cual la Corona tenía el compromiso de recompensar el esfuerzo llevado a cabo por conquistadores y primeros pobladores, ya fuera con el propio botín de guerra, cargos públicos, tierras y especialmente encomiendas (Serrera Contreras 1992: 487). Merece la pena volver de nuevo a la carta remitida a su esposa para encontrar un claro testimonio de su pensamiento al respecto y la legitimidad del premio por los servicios prestados a que se consideraba acreedor. El texto es bien explícito:

«Yo, señora, he hecho a S.M. tan gran servicio en ganarle estos reynos de tales tiranos $y$ tan bien armados...; y con todo esto, y más que dirá el mensajero, me di tan buena maña y diligencia que uve dyneros y gente y armas y caballos y lo que fue más necesario para los vencer y ganar...; que de tales servicios y albricias no es nada darme todo esto que pido, que más razón era que S.M. me diese más de lo que pido, pues le di estos reynos, y por semejantes cosas y de menos servicio a otros estados... y pues yo, señora, lo he trabajado y lo merezco, bien es que allá se trabaje para aver algún provecho y se profie que lo hagan, porque destos servicios tales que hacen caballeros, se suelen comenzar las casas y mayorazgos» (Cartas de Indias 1974, II: 496). 
No cabe duda de que estaba posicionado del lado de los encomenderos, dispuesto a obtener rentabilidad de aquel sistema y aprovechar las relaciones sociales de raíz medieval y fuertes reminiscencias feudales que conllevaba. Defendió la continuidad del modelo antillano que implicaba tanto el tributo como el trabajo del indio, lo que en la práctica permitía a los encomenderos ejercer control total sobre la vida y bienes de aquél. Desde esta perspectiva, es posible plantear una indudable similitud con la línea argumental ideológica esgrimida por Gonzalo Pizarro durante el conflicto que le enfrentó con el virrey Blasco Núñez Vela. El sustrato cultural y medieval de aquella generación jugó un papel determinante a la hora de acomodar y justificar los actos de aquellos protagonistas y nuestro licenciado no fue una excepción (Lohmann Villena 1977; Angeli 2012: 105-122). Entonces, contemplada desde tales presupuestos, la conducta de Vaca de Castro no sólo no era reprobable sino que, por el contrario, poseía plena legitimidad y así trató de presentarla con éxito ante sus detractores una década después.

Sin embargo, hasta ese momento la opinión imperante jugaba en su contra. Al menos desde 1536, la Corte era cada vez más proclive a las ideas que demandaban reformas sustanciales en el sistema de encomiendas y así se tradujo en los sucesivos documentos oficiales empeñados en recortar las aspiraciones feudales del grupo conquistador. Esta circunstancia y la coyuntura de transición en la que se desenvolvió pueden explicar la contradicción evidente de un Vaca de Castro aferrado en la práctica a las viejas concepciones medievales, por un lado, y alineado a los nuevos postulados lascasistas, por otro. La minería fue, entre otras cuestiones, la piedra angular que puso de manifiesto la lucha de nuestro personaje entre las apetencias señoriales de raíz feudal y la dirección política del monarca, empeñada en cercenarlas.

\section{Notas}

1 Véase en este mismo volumen la aportación de Dominika Sieczkowska y Donato Amado sobre Ordenanzas de Tambos cusqueños del Licenciado Christobal Baca de Castro en comparación con datos arqueológicos.

2 Este conjunto normativo puede encontrarse en AGI, Lima, 566, en su libro 4 que contiene el registro de oficio y partes desde el 15 de junio de 1540 hasta el 6 de julio de 1543.

3 El original de estas ordenanzas se encuentra en AGI, Patronato 170, Ramo 47.

4 Nos remitimos al completo estudio realizado por Hélène Roy bajo el título La ejecutoria del pleito contra don Cristóbal Vaca de Castro: paleografía y análisis de un manuscrito "peruano" del Archivo del Sacro Monte, que se publica en este volumen. 


\section{Referencias citadas}

Angeli, Sergio Hernán

2012 Palabras que no fueron olvidadas: La pervivencia del discurso jurídico medieval en el alzamiento de Gonzalo Pizarro (Perú 1544-1548). Revista jurídica Universidad Autónoma de Madrid 26: 105-122.

Barnadas, Josep M.

1973 Charcas. Orígenes de una sociedad colonial. 635 pp. Centro de Investi-

Cartas de Indias gación y Promoción del Campesinado, La Paz.

1974 [1877] Recogidas por el Excelentísimo señor Conde de Toreno. Tomo II. 699 pp. Biblioteca de Autores Españoles 265. Atlas, Madrid.

Cieza de León, Pedro

1984 [1553] La crónica del Perú (edición e introducción de Manuel Ballesteros). 414 pp. Historia 16, Crónicas de América 4, Madrid.

1985 Obras completas, II. Las guerras civiles peruanas. Guerra de Chupas (edición de Carmelo Sáenz de Santamaría). 626 pp. Consejo Superior de Investigaciones Científicas/Instituto Gonzalo Fernández de Oviedo, Madrid.

García Rodríguez, Casiano

1957 Vida de D. Cristóbal Vaca de Castro, Presidente y gobernador del Perú. 297 pp. Ediciones Religión y Cultura, Madrid.

Garcilaso de la Vega, Inca

1960 [1617] Historia General de Perú. Segunda parte de los Comentarios reales de los incas (edición y estudio preliminar de Carmelo Sáenz de Santamaría). 554 pp. Biblioteca de Autores Españoles 132. Atlas, Madrid.

Hampe Martínez, Teodoro

1990 Fray Domingo de Santo Tomás y la encomienda de indios en Perú (1540-1570). En Los dominicos y el Nuevo Mundo. Actas del II Congreso Internacional, editado por José Barrado, O.P., pp. 355-402. Editorial San Esteban, Salamanca.

1981 La actuación del Obispo Vicente de Valverde en el Perú. Historia y Cultura 13/14: 109-153.

Hanke, Lewis

1967 La lucha española por la justicia en la conquista de América. 335 pp. Aguilar, Madrid.

Hanke, Lewis (editor)

1978 Los virreyes españoles en América durante el gobierno de la Casa de Austria. Perú. Tomo I. 299 pp. Biblioteca de Autores Españoles 280. Atlas, Madrid. 
Helmer, Marie

1959 Notas sobre la encomienda peruana en el siglo XVI. Revista del Instituto de Historia del Derecho 10: 124-143.

Lohmann Villena, Guillermo

1977 Las ideas jurídico políticas en la rebelión de Gonzalo Pizarro. La tramoya doctrinal del levantamiento contra las Leyes Nuevas en el Perú. 112 pp. Seminario Americanista de la Universidad de Valladolid, Valladolid.

López de Gómara, Francisco

1979 [1552] Historia general de las Indias. Hispania victrix (prólogo de Jorge Gurría Lacroix). XXXIII + 373 pp. Biblioteca Ayacucho 64, Caracas.

López-Ocón Cabrera, Leoncio

1987 Andinología, lascasismo y humanismo cristiano. La defensa de las sociedades andinas del quechuista fray Domingo de Santo Tomás. 384 pp. Tesis de Maestría en Historia Andina, dirigida por John V. Murra, Facultad Latinoamericana de Ciencias Sociales, Quito.

Muro Orejón, Antonio

1959 Las Nuevas Leyes de 1542-1543. Anuario de Estudios Americanos XVI: 561-619.

Osuna Fernández-Largo, Antonio

1991 Ética y política en las Leyes de Indias del siglo XVI. Anuario de Filosofía del Derecho VIII: 77-102.

Paniagua Pérez, Jesús

1988 Don Cristóbal Vaca de Castro, un leonés del siglo XVI en el Nuevo Mundo. Tierras de León 28 (71): 61-72.

Pérez de Tudela Bueso, Juan

1958 La gran reforma carolina de las Indias en 1542. Revista de Indias XVIII 73/74: 463-506.

Pérez de Tudela, Juan (editor)

1963 Crónicas del Perú. 384 pp. Biblioteca de Autores Españoles 164, Atlas, Madrid.

1964 Documentos relativos a don Pedro de la Gasca y a Gonzalo Pizarro, I. 608 pp. Real Academia de la Historia, Madrid.

Puente Brunke, José de la

1992 Encomienda y encomenderos en el Perú. 536 pp. Diputación Provincial de Sevilla, Sevilla.

Sancho de la Hoz, Pedro

1917

Relación de la conquista del Perú (notas biográficas y concordancia de Horacio Urteaga; biografía de Carlos A. Romero). XXI+224 pp. Colección de Libros y Documentos Referentes a la Historia del Perú, vol. V. Imprenta y Librería Sanmartí, Lima. 
Santisteban Ochoa, Julián

1948 Fr. Vicente Valverde, Protector de los Indios y su obra. Revista de Letras. Facultad de Letras de la Universidad Nacional del Cuzco I (2): 117176.

Serrera Contreras, Ramón María

1992 Derecho premial y aspiraciones señoriales en la primera generación de la conquista. En Congreso Internacional del Descubrimiento (14921556). Actas, Tomo III, pp. 481-502. Real Academia de la Historia, Madrid.

Viforcos Marinas, María Isabel y Jesús Paniagua Pérez

1991 El leonés don Cristóbal Vaca de Castro: gobernador y organizador del Perú. 151 pp. S.A. Hullera Vasco-Leonesa, Madrid.

Zavala, Silvio

1978 El servicio personal de los indios en el Perú. Tomo I. 360 pp. El Colegio de México, México. 
